\title{
Mechanism of Water Splitting on Gadolinium-Doped CeO2(111): A DFT + U Study
}

\author{
Wu, Tiantian; Deng, Qingming; Hansen, Heine Anton; Vegge, Tejs
}

Published in:

Journal of Physical Chemistry C

Link to article, DOI:

10.1021/acs.jpcc.8b12037

Publication date:

2019

Document Version

Peer reviewed version

Link back to DTU Orbit

Citation (APA):

Wu, T., Deng, Q., Hansen, H. A., \& Vegge, T. (2019). Mechanism of Water Splitting on Gadolinium-Doped CeO2(111): A DFT + U Study. Journal of Physical Chemistry C, 123(9), 5507-5517. https://doi.org/10.1021/acs.jpcc.8b12037

\section{General rights}

Copyright and moral rights for the publications made accessible in the public portal are retained by the authors and/or other copyright owners and it is a condition of accessing publications that users recognise and abide by the legal requirements associated with these rights.

- Users may download and print one copy of any publication from the public portal for the purpose of private study or research.

- You may not further distribute the material or use it for any profit-making activity or commercial gain

- You may freely distribute the URL identifying the publication in the public portal 


\section{Mechanism of Water Splitting on Gadolinium}

\section{Doped $\mathrm{CeO}_{2}(111):$ A DFT+U Study}

Tiantian Wu, Qingming Deng, Heine Anton Hansen* and Tejs Vegge*

Department of Energy Conversion and Storage, Technical University of Denmark, Fysikvej, 2800 Kgs. Lyngby, Denmark.

*Corresponding authors:

Prof. Dr. Tejs Vegge $\quad$ E-mail: teve@dtu.dk Tel: +45 45258201

Assoc. Prof. Dr. Heine Anton Hansen E-mail: heih@dtu.dk Tel: +45 46775758 


\begin{abstract}
Ceria-based materials have attracted considerable interest due to their potential applications in the electrocatalytic splitting of water for hydrogen production. In this work, the reaction mechanism of water splitting on gadolinium-doped ceria (GDC) is investigated using DFT $+\mathrm{U}$ calculations. We found that $\mathrm{H}_{2}$ evolution preferentially proceeds on the overly hydroxylated surfaces of pure ceria and GDC via the formation of $\mathrm{Ce}-\mathrm{H}$ and $\mathrm{Gd}-\mathrm{H}$ intermediates respectively, which is much more efficient than the $\mathrm{H}_{2}$ evolution over their partially hydroxylated surfaces. Notably, GDC is more easily and strongly reduced through formation of oxygen vacancies and hydroxyls compared to pure ceria. Thus, the facile formation of the overly hydroxylated states by the incorporation of Gd leads to the improved electrocatalytic activity of water splitting on ceria. These results indicate that a dopant that stabilizes the reduced ceria and favors the formation of Metal-H moiety is capable of effectively improving the reaction activity of ceria for water splitting.
\end{abstract}




\section{INTRODUCTION}

Ceria is widely used in many catalytic processes not only as a support but also as an efficient catalyst in redox reactions, due to its particular redox cycle between $\mathrm{Ce}^{4+}$ and $\mathrm{Ce}^{3+}$. Ceria can be used to store oxygen in three-way catalysts ${ }^{1-3}$ and in the water-gas shift reaction ${ }^{4-6}$. It also provides a sustainable alternative to fuel production using solar thermochemical cycles, with high conversion efficiencies. ${ }^{7,8}$ As a good ionic or mixed ionic and electronic conductor, doped ceria is a promising material for oxygen ion-conducting solid electrolytes in solid oxide fuel cells $(\mathrm{SOFC})^{9,10}$ and solid oxide electrolyser cells (SOEC). ${ }^{11,12}$

SOEC is a highly efficient technology for hydrogen production through the water splitting reaction at high temperature. By utilization of waste heat at high temperature, an SOEC can produce hydrogen with smaller overpotential losses than low temperature electrolysis cells. ${ }^{13}$ There is, however, pronounced degradation at the electrochemical interfaces (gas/electrode/electrolyte boundaries) in SOEC during high operating temperature, which results from oxygen incorporation into the oxygen conductor, eventually weakening and cracking the reaction interface. ${ }^{13,14}$ The hydrogen evolution reaction (HER) usually takes place at triple phase boundaries (TPB) between the gas channels, electronic and ionic conductors. The efficiency of the HER is significantly restricted by the degradation. ${ }^{13,14}$ Replacing the traditional yttriastabilized zirconia (YSZ) ionic conductor with ceria will extend the TPB reaction zones to a double-phase boundary, where HER proceeds readily at the ceria-gas interface. ${ }^{15,16}$ Computational studies has showed that water dissociation for hydrogen production at the ceria/gas interface would be facile once oxygen vacancies can diffuse to the surface. ${ }^{17}$ Improved ionic conductivity increases the reaction efficiency of ceria, and doping ceria is a promising 
approach for improving the ionic conductivity and the electrochemical activity for HER. Gadolinium doped ceria has been demonstrated to have the highest ionic conductivity among ceria-based materials ${ }^{18}$ and allows the electrochemical reactions at intermediate temperatures (773-1073 K). ${ }^{19,20}$ Therefore, ceria-based materials are promising for hydrogen production, through $\mathrm{H}_{2} \mathrm{O}$ electrolysis in SOEC.

In the past few decades, the reactions associated with $\mathrm{H}_{2}, \mathrm{H}_{2} \mathrm{O}$ and ceria have been studied extensively, showing that the catalytic behavior of ceria is directly linked to its mixed valence $\mathrm{Ce}^{3+} / \mathrm{Ce}^{4+}$ redox states and the mobility of oxygen ions. ${ }^{11,17,21}$ Recently, the excellent performance of solar thermochemical redox reactions in ceria has been shown to be attributed to the positive entropy contribution associated with the $f^{0} \rightarrow f^{1}$ transition. ${ }^{22}$ Electrocatalytic water splitting in ceria includes reaction steps of oxygen vacancy diffusion to the surface, water adsorption on the surface, water reaction with the oxygen vacancy and oxygen ions into hydroxyl $\left(\mathrm{H}_{2} \mathrm{O}_{\text {ads }}+2 \mathrm{Ce}^{3+}+\mathrm{V}_{\mathrm{o}}+\mathrm{O}^{2-} \rightarrow 2 \mathrm{OH}^{-}+2 \mathrm{Ce}^{3+}\right)$, and finally hydroxyl decomposition into $\mathrm{H}_{2}$ and oxygen ions $\left(2 \mathrm{OH}^{-}+2 \mathrm{Ce}^{3+} \rightarrow \mathrm{H}_{2}+2 \mathrm{Ce}^{4+}+2 \mathrm{O}^{2-}\right)$. A competing pathway for the water splitting reactions when lattice $\mathrm{O}^{2-}$ is unavailable at the ceria surface proceeds through a Ce-H intermediate $\left(\mathrm{H}_{2} \mathrm{O}_{\text {ads }}+2 \mathrm{Ce}^{3+}+\mathrm{V}_{\mathrm{o}} \rightarrow \mathrm{OH}^{-}+\mathrm{Ce}^{4+}+\mathrm{Ce}^{4+} H^{-} \rightarrow \mathrm{H}_{2}+2 \mathrm{Ce}^{4+}+\mathrm{O}^{2-}\right) \cdot{ }^{17}$ The localization of the excess electrons after creating an oxygen vacancy varies with different DFT descriptions of the $4 \mathrm{f}$ orbitals on cerium. ${ }^{17,23,24}$ Oxygen diffusion to the surface for reaction with adsorbed water and the following step of water dissociation into stable hydroxyl are facile steps, having barriers of 0.65 and $0.06 \mathrm{eV}$, respectively. ${ }^{17}$ Recently, both theoretical and experimental studies indicate that the rate-determining step of the water splitting reaction on ceria involves the charge transfer for $\mathrm{H}_{2}$ production through hydroxyl decomposition. ${ }^{11,17}$ Experimentally, surface hydroxyls can be stabilized up to $400-600 \mathrm{~K}$ under UHV conditions. ${ }^{25,26}$ Increasing the surface 
reduction by creating oxygen vacancies or forming hydroxyls can improve the reaction activity for $\mathrm{H}_{2}$ production. ${ }^{17,27}$ Among ceria-based materials, GDC holds great promise to improve the water splitting reaction rate. ${ }^{18-20}$ So far, computational studies on GDC have been limited to electronic structures and properties related to oxygen diffusion. ${ }^{28-30}$ Therefore, the fundamental understanding of the reaction mechanism for water splitting in SOEC on pure ceria and especially doped ceria remains elusive.

In this work, we present detailed DFT investigations on the formation and diffusion of oxygen vacancies, as well as hydroxyl formation and decomposition on ceria and GDC, respectively. The effect of Gd-doping on the stability of the reduced ceria surface by creating oxygen vacancies and formation of hydroxyl groups, and the impact of Gd-doping on the reaction pathways for water dissociation are discussed to obtain a more clear understanding of the water splitting reaction on the reduced ceria-based materials.

\section{METHODS}

Density-functional-theory (DFT) calculations are performed using the Vienna Ab-initio Simulation Package (VASP). ${ }^{31-33}$ The ionic cores are described by PAW potentials ${ }^{34}$ and the wave functions are expanded in plane waves with an energy cutoff of $550 \mathrm{eV}$. The exchange and correlation are approximated by the PBE functional ${ }^{35}$ including aspherical gradient corrections within the PAW augmentation spheres. Because of the electron self-interaction error in the Kohn-Sham formalism, the DFT+U approach ${ }^{36}$ was used to describe electron localization on the 4f states of $\mathrm{Ce}^{3+}$. We do not include a $\mathrm{U}$ correction on gadolinium, because the $4 \mathrm{f}$ shell of gadolinium is always found to be filled with seven electrons $\left(4 f^{7}\right)$ and the $U$ contribution on describing the electron localization on the $4 \mathrm{f}^{7}$ shell can be negligible ${ }^{37}$. the Spin polarization was 
considered with ferromagnetic ordering, because the energy difference between antiferromagnetic and ferromagnetic state is small $(<0.01 \mathrm{eV}) .^{38}$

The optimal value of the Hubbard $U$ parameter for cerium varies in the range of $0<U_{\text {eff }}<10$ $\mathrm{eV}\left(\mathrm{U}_{\text {eff }}=\mathrm{U}-\mathrm{J}\right)$ depending on the quantity of interest. ${ }^{36,39-41} \mathrm{PBE}+\mathrm{U}$ usually overestimates the lattice constant. ${ }^{40,41}$ The reduction energy of ceria is well described already at $\mathrm{U}_{\text {eff }} \approx 2.0 \mathrm{eV}^{39}$ while the calculated band gap is consistent with experiments for $\mathrm{U}_{\text {eff }}>5.5 \mathrm{eV}^{40}$. We find a strong dependence of the oxygen vacancy formation energy $\left(\mathrm{E}_{\mathrm{V}_{0}}\right)$ and the barrier for hydroxyl

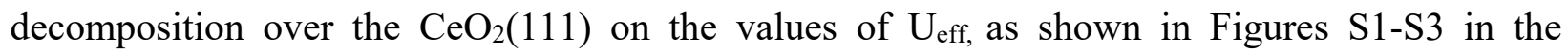
supporting information. As noted in Figure $\mathrm{S} 1, \mathrm{E}_{\mathrm{Vo}}$ linearly decreases with increasing $\mathrm{U}_{\text {eff }}$ when $\mathrm{U}_{\text {eff }}$ is higher than $3.5 \mathrm{eV}$. For $\mathrm{U}_{\text {eff }}<3.5 \mathrm{eV}$ there is a zone of weak electron localization on the $4 \mathrm{f}$ orbitals of ceria, which is consistent with the results by Castleton et al. that charge starts to become localize at $\mathrm{U}_{\text {eff }} \approx 3.0 \mathrm{eV}^{40}$. The degree of localization reaches a maximum at $\mathrm{U}_{\text {eff }} \approx 5.5 \mathrm{eV}$ for the GGA+U method. ${ }^{40}$ The calculated barrier for hydroxyl decomposition on the $\mathrm{CeO}_{2}(111)$ increases with $U_{\text {eff }}$ because of the higher stability of reduced cerium when using a larger $U_{\text {eff }}$ as shown in Figure $\mathrm{S} 3$ and $\mathrm{S} 4$. Overall, $\mathrm{U}_{\mathrm{eff}}=4.5 \mathrm{eV}$ is often used for investigations on vacancy diffusion and related reactions on ceria, which has been proved to be an appropriate correction to ensure describe chemical properties of ceria. ${ }^{42-45}$ In addition, the vacancy formation energy and the activation barrier for hydroxyl decomposition on the $\mathrm{CeO}_{2}(111)$ calculated in this work are well consistent with previously reported DFT results. ${ }^{23,45,46}$ Thus, $\mathrm{U}_{\text {eff }}=4.5 \mathrm{eV}$ used in this work is appropriate to describe the electrochemical properties of ceria during the water splitting reaction.

The $\mathrm{CeO}_{2}(111)$ surface is built as a $2 \times 3$ repeated surface unit cell consisting of nine atomic layers $\left(\mathrm{Ce}_{18} \mathrm{O}_{36}\right)$. Three atomic layers in the bottom are fixed as shown in Figure $\mathrm{S} 4$ in the 
Supporting Information. Vacuum with a thickness of $15 \AA$ is added to reduce interaction between the periodic images. The calculated equilibrium lattice constant of bulk ceria is $5.497 \AA$, which is well consistent with reported DFT result ${ }^{28,45}$ but overestimates the experimental lattice constant of $5.411 \AA^{47}$ by $1.6 \%$. The lattice constant has a $1.4 \%$ mismatch with the experimental lattice constant of $\mathrm{Ce}_{0.8} \mathrm{Gd}_{0.2} \mathrm{O}_{1.9}(5.423 \AA)^{48}$. The lattice with the same mismatch has been used by Aparicio-Anglès et al. for investigations of dopant clustering near the GDC(111) surface. ${ }^{28}$ The highest ionic conductivity is obtained in ceria with $10 \% \mathrm{Gd}$ doping. ${ }^{28,49}$ In this work, two cerium atoms in $\mathrm{Ce}_{18} \mathrm{O}_{36}$ (111) are replaced with two gadolinium atoms for a $\mathrm{Gd}$ conce ntration of $11 \%$. The selected system size allows for investigations of compensating oxygen vacancies near the optimal doping level, because two $\mathrm{Gd}^{3+}$ dopants are expected to induce the formation of one oxygen vacancy. The $\mathrm{Gd}_{2} \mathrm{Ce}_{16} \mathrm{O}_{35}$ (111) surface was investigated as the GDC model.

Transition states (TS) are identified for oxygen vacancy diffusion, water dissociation into hydroxyls and hydroxyl decompositions, using the climbing image nudged-elastic band method ${ }^{50}$ in VASP. Each band is optimized until the maximum force on the band is less than $0.03 \mathrm{eV} / \AA$.

\section{RESLUTS AND DISCUSSIONS}

\section{Distribution of $\mathrm{Gd}$ and oxygen vacancies (Vo) in $\mathrm{Gd}_{2} \mathrm{Ce}_{16} \mathrm{O}_{35}(111)$. We first} investigate the surface without a compensating oxygen vacancy by substituting one Gd atom into the surface layer and another $\mathrm{Gd}$ atom into either the surface or subsurface layer. The distribution of the two Gd atoms is labeled from Type1 to Type4 with increasing Gd-Gd distance as shown in Figure 1(a). The uncompensated situation was normally investigated for aliovalent dopants in $\mathrm{CeO}_{2}{ }^{28,37}$. Based on the four uncompensated configurations of the $\mathrm{Gd}_{2} \mathrm{Ce}_{16} \mathrm{O}_{36}(111)$, a 
compensating oxygen vacancy (Vo) was then introduced into the different oxygen atomic layers leading to the formation of the $\mathrm{Gd}_{2} \mathrm{Ce}_{16} \mathrm{O}_{35}(111)$. The Vo formation energy is defined as:

$$
E_{V o}=E_{G d_{2} C e_{16} O_{35}}-E_{G d_{2} C e_{16} O_{36}}+\frac{1}{2} E_{O_{2}},
$$

where $E_{G d_{2} C e_{16} O_{35}}$ is the total energy of the system after creating one oxygen vacancy, $E_{G d_{2} \mathrm{Ce}_{16} \mathrm{O}_{36}}$ is the total energy of the uncompensated system and $E_{O_{2}}$ is the energy of an oxygen molecule. The formation energy of one oxygen vacancy in the subsurface $\left(\mathrm{Vo}^{\text {subsurface }}\right)$ and top surface $\left(\mathrm{Vo}^{\text {surface }}\right)$ in the uncompensated system to form $\mathrm{Gd}_{2} \mathrm{Ce}_{18} \mathrm{O}_{35}$ (111) is list in Table 1 . Creating a $\mathrm{Vo}^{\text {subsurface }}$ in Type 3 is more facile than in other types of Gd distribution, which is taken as a reference. Compared with the $\mathrm{Vo}^{\text {subsurface }}$ in Type3, the relative energy of the Vo in each oxygen atomic layer in $\mathrm{Gd}_{2} \mathrm{Ce}_{16} \mathrm{O}_{35}(111)$ with four types of $\mathrm{Gd}$ distribution as a function of the distance from the top oxygen layer (depth) is given in Figure 1(b). For Type 1 GDC, the Vo favors to be created in the top surface, in comparison with creating one Vo in the subsurface and deeper layers. However, for Type2, Type 3 and Type 4 with two gadolinium atoms siting in two different atomic layers, the most favorable oxygen vacancy sits in the subsurface oxygen layer. The relative energy of the Vo in these GDC model increases when the vacancy is created in the deeper oxygen layers (depth $>1.5 \AA$ ) and the two excess electrons remain localized on the two gadolinium atoms. The energy difference between the $\mathrm{Vo}^{\text {surface }}$ with four types of $\mathrm{Gd}$ distribution is lower than $0.006 \mathrm{eV}$, as displayed in Table1. Compared to the $\mathrm{Vo}^{\text {surface }}$, a slightly larger energy difference (within $0.23 \mathrm{eV}$ ) between the $\mathrm{Vo}^{\text {subsurface }}$ is noticed, which is consistent with AparicioAnglès's findings (within $0.25 \mathrm{eV}$ ) ${ }^{28}$. However, the energy difference between the four different types of $\mathrm{Gd}$ distribution in $\mathrm{Gd}_{2} \mathrm{Ce}_{16} \mathrm{O}_{36}$ is within $0.065 \mathrm{eV}$ as presented in the Table 1. In addition, we found that the calculated energy difference between the formation energy of $\mathrm{Gd}_{2} \mathrm{Ce}_{18} \mathrm{O}_{35}$ (111) having one oxygen vacancy in the top surface with four types of $\mathrm{Gd}$ 
distributions is $<0.066 \mathrm{eV}$. With an oxygen vacancy in the subsurface, the energy difference is $<0.291 \mathrm{eV}$ (see Table S1 in the supporting information). Our results suggest that Gd can distribute freely between the top surface or subsurface of $\mathrm{Gd}_{2} \mathrm{Ce}_{16} \mathrm{O}_{35}(111)$ at $11 \% \mathrm{Gd}$ concentration. These results are in line with the previously reported findings. ${ }^{28}$

In addition, the calculated formation energy of an oxygen vacancy in the top surface of the clean $\mathrm{Ce}_{18} \mathrm{O}_{36}(111)$ is $2.18 \mathrm{eV}$, which is close to $2.15 \mathrm{eV}$ calculated by using $\mathrm{p}(3 \times 3)$ unit cell and $\mathrm{U}_{\text {eff }}=4.5 \mathrm{eV}^{45}$. The calculated formation energy for a slightly lager $\mathrm{p}(3 \times 4)$ unit cell is only 0.16 $\mathrm{eV}$ smaller than using a $\mathrm{p}(2 \times 3)$ unit cell, agreeing well with the report by Hui-Ying et al ${ }^{51}$ that the interaction between $\mathrm{O}$ vacancy in neighboring supercells could be neglected. Because the inducing of a compensating oxygen vacancy into the uncompensated $\mathrm{Gd}_{2} \mathrm{Ce}_{16} \mathrm{O}_{36}$ system is preferred, the Vo formation energies in $\mathrm{Gd}_{2} \mathrm{Ce}_{16} \mathrm{O}_{36}$ with four types of $\mathrm{Gd}$ distribution are negative values.

(a)

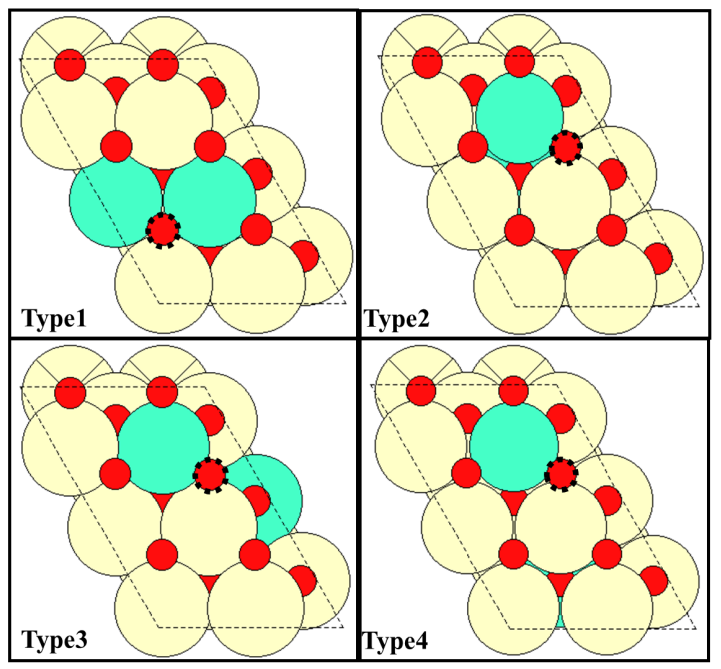

(b)

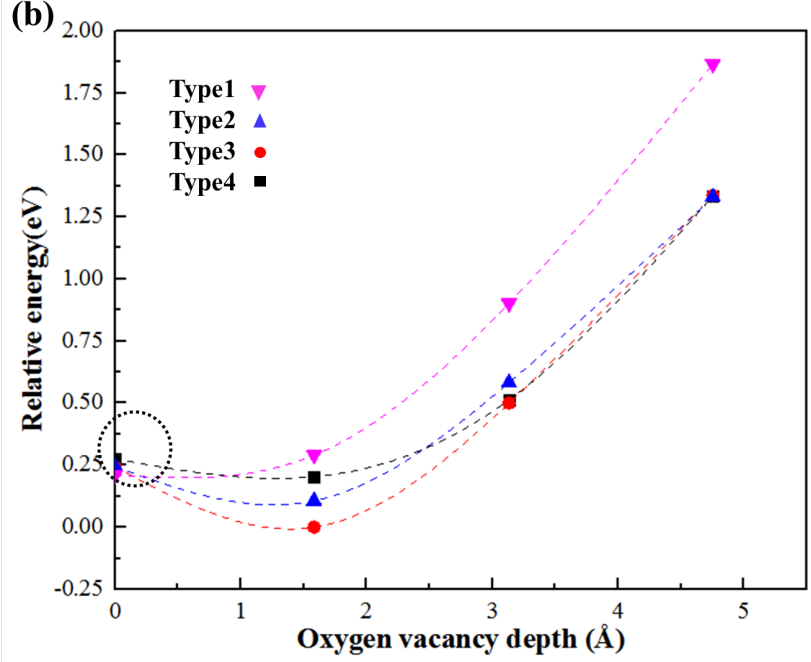

Figure 1: (a) The configurations of the most favorable vacancy in the top surface (depth $=0.0 \AA$ ) of the $\mathrm{Gd}_{2} \mathrm{Ce}_{16} \mathrm{O}_{35}(111)$ with Type1, Type2, Type3 and Type4 $\mathrm{Gd}$ distribution. Color legend: yellow for cerium, green for gadolinium and red for oxygen atoms. The balls with crosses represent the fixed atoms, while red balls with a dashed perimeter marks the oxygen vacancy. (b) 
Relative energy of an oxygen vacancy at different depths in the $\mathrm{Gd}_{2} \mathrm{Ce}_{16} \mathrm{O}_{35}(111)$ with four types of Gd distribution. The depth is measured from the top of the surface.

Table 1. The minimum Gd-Gd distance in the four types of $\mathrm{Gd}$ distribution in the $\mathrm{Gd}_{2} \mathrm{Ce}_{16} \mathrm{O}_{36}$ (111) and the relative energy between them. The formation energy of one oxygen vacancy (Vo) in the uncompensated system to form the $\mathrm{Gd}_{2} \mathrm{Ce}_{18} \mathrm{O}_{35}$ (111). Vo in the subsurface and in the top surface layer is abbreviated as $\mathrm{Vo}^{\text {subsurface }}$ and $\mathrm{Vo}^{\text {surface }}$, respectively.

\begin{tabular}{ccccc}
\hline Gd distribution type & $\mathrm{Gd}-\mathrm{Gd}$ Distance $/ \AA$ & Relative Energy/eV & $\mathrm{Vo}^{\text {subsurface }} / \mathrm{eV}$ & $\mathrm{Vo}^{\text {surface }} / \mathrm{eV}$ \\
\hline Type1 & 3.982 & 0 & -0.725 & -0.783 \\
Type2 & 4.014 & 0.040 & -0.927 & -0.789 \\
Type3 & 5.489 & 0.039 & -0.957 & -0.787 \\
Type4 & 6.717 & 0.065 & -0.855 & -0.783 \\
$\mathrm{Ce}_{18} \mathrm{O}_{36}(111)$ & $/$ & $/$ & 1.808 & 2.184 \\
\hline
\end{tabular}

Reduced GDC and ceria. Increased surface reduction has been observed to improve the activity for $\mathrm{H}_{2}$ production. ${ }^{17,27}$ In the following, we investigate reduced ceria and GDC with oxygen vacancies (Vo) and hydroxyls formed by water dissociation on lattice oxygen ions. For ceria, the surface reduction reactions can be written as $2 \mathrm{Ce}^{4+}+\mathrm{O}^{2-} \rightarrow 2 \mathrm{Ce}^{3+}+\mathrm{V}_{O}+\frac{1}{2} \mathrm{O}_{2}$ and $\mathrm{H}_{2} \mathrm{O}_{\text {ads }}+2 \mathrm{Ce}^{3+}+\mathrm{V}_{\mathrm{o}}+\mathrm{O}^{2-} \rightarrow 2 \mathrm{OH}^{-}+2 \mathrm{Ce}^{3+}$. The hydroxylated GDC forms via similar reactions. The magnetization of the reduced cerium or gadolinium atoms are labeled and presented in the Figures S5-S7 in the supporting information. Among the four considered types of Gd distribution, the Vo formation energies in Type2 and Type 3 are the lowest. Because the formation energy of oxygen vacancies in Type 2 and Type 3 are very close, only Type 2 is considered for the further investigations. Although the subsurface Vo in Type1 is $0.202 \mathrm{eV}$ less stable than the subsurface Vo in Type2, the difference in the formation energy of a Vo in the top surface of Type 1 and Type 2 is very small $(6 \mathrm{meV})$, which indicates a similar reactivity of the top 
surface vacancy in GDC regardless of the distribution of the Gd. A comparison of the most favorable configurations of hydroxylated surfaces and mixed hydroxyl-vacancy phases, among Type1, Type2 and ceria is presented in the Figures S5-S7 in the supporting information. Here, the hydroxyl coverage $\theta_{\mathrm{H}}=\mathrm{N}_{\mathrm{H}} / \mathrm{N}$ is used to distinguish surfaces with different degrees of reduction by forming hydroxyls, which is defined as the number of hydroxyls $\left(\mathrm{N}_{\mathrm{H}}\right)$ in to the total number of oxygen $(\mathrm{N}=6)$ in the top layer. The more reduced surfaces have higher coverage of hydroxyls.
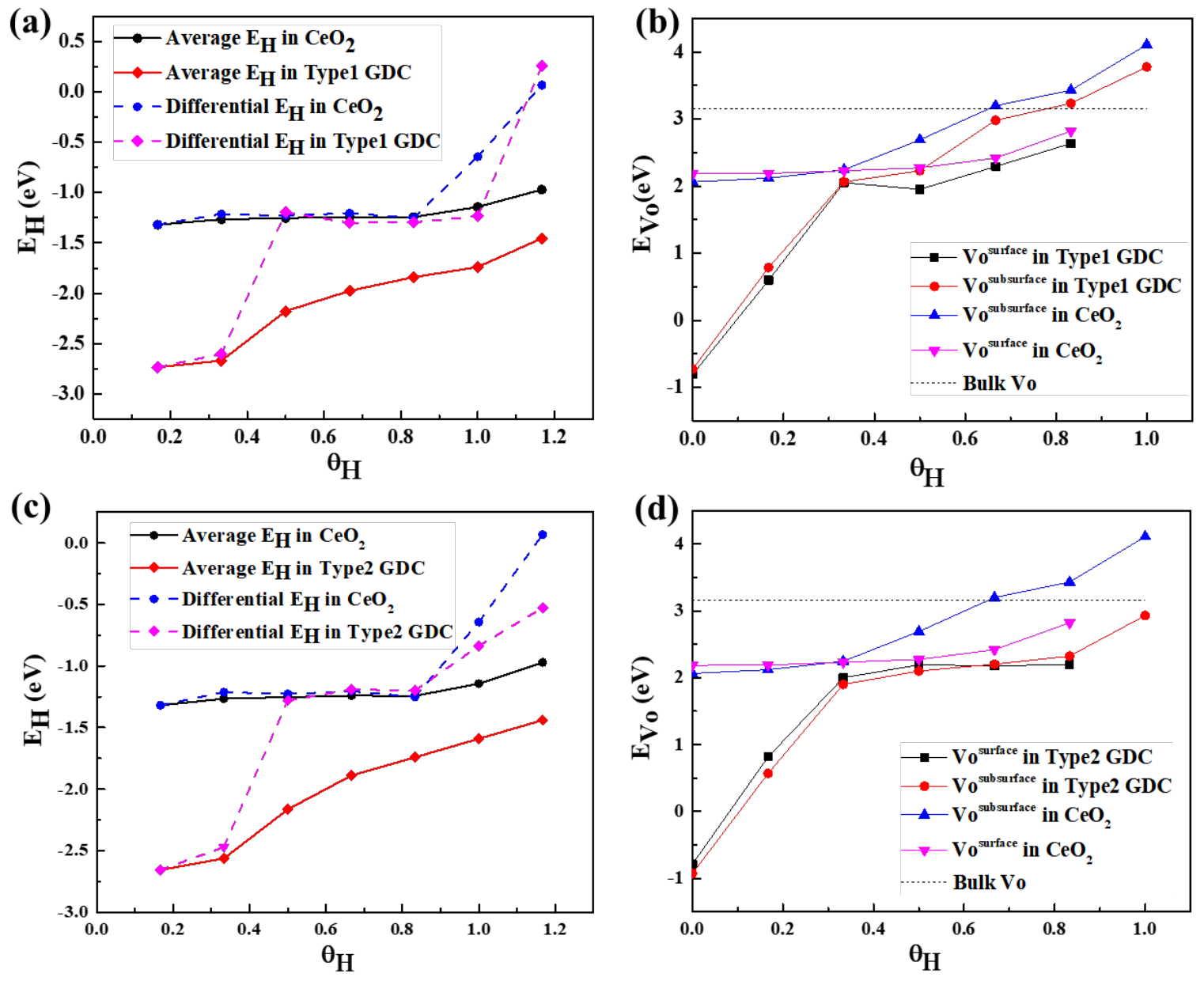
Figure 2. The formation energy of hydroxyl $\left(\mathrm{E}_{\mathrm{H}}\right)$ as a function of hydroxyl coverage $\left(\theta_{\mathrm{H}}\right)$ in Type1 GDC (a) and Type2 GDC (c), compared with the $\mathrm{E}_{\mathrm{H}}$ in the $\mathrm{CeO}_{2}$; The formation energy of creating an oxygen vacancy ( $\left.\mathrm{E}_{\mathrm{Vo}}\right)$ as a function of $\theta_{\mathrm{H}}$ in Type1 GDC (b) and Type2 GDC (d), compared with the $\mathrm{E}_{\mathrm{V}_{0}}$ in the $\mathrm{CeO}_{2}$.

Figure 2 shows the average and differential formation energy of hydroxyls, $\mathrm{E}_{\mathrm{H}}$, and oxygen vacancy formation energies, $\mathrm{E}_{\mathrm{V}}$, as a function of hydroxyl coverage in Type1 and Type2 GDC compared to ceria. As noticed from Figure 2, the average $E_{H}$ increases with the increasing $\theta_{H}$. When the GDC surface has one or two hydroxyls, the differential $\mathrm{E}_{\mathrm{H}}$ in GDC is about $1.4 \mathrm{eV}$ more negative than in ceria, which again is due to the strong driving force to create $\mathrm{Gd}^{3+}$ rather than $\mathrm{Ce}^{3+}$. The magnetization of the reduced cerium or gadolinium atoms is shown in Figures S5$\mathrm{S} 7$ in the supporting information. After two hydroxyls form on GDC, $\mathrm{Ce}^{4+}$ ions are reduced to $\mathrm{Ce}^{3+}$ near these surface hydroxyls because of the further reduction, leading to the differential $\mathrm{E}_{\mathrm{H}}$ in Type1 and Type 2 close to that in ceria as hydroxyl coverage ranging from 0.5 to 0.83 . Forming one more hydroxyl at higher $\theta_{\mathrm{H}}$, the differential $\mathrm{E}_{\mathrm{H}}$ increases dramatically, which indicates the repulsive interaction between the hydroxyls and the reduced surface. When the hydrogen coverage increases beyond 1.0, the additional hydrogen reacts with subsurface oxygen ions to form one subsurface hydroxyl (subO-H), which is unfavorable compared to surface hydroxyls. The differential energy required for the formation of the subO-H in Type2 GDC is much more negative than that in ceria and Type 1 GDC, which means that the formation of the subO-H is relatively favorable in Type 2 GDC. Overall, the average $\mathrm{E}_{\mathrm{H}}$ in both Type1 and Type 2 GDC is much more negative than that in ceria. Therefore, the reduced ceria via forming hydroxyls is significantly favorable by incorporation of Gd. 
At the hydroxylated surfaces, $E_{V_{o}}$ increases with increasing coverage of hydroxyls. However, $\mathrm{E}_{V_{0}}$ in GDC is more negative than in ceria, which reveals that creating a $\mathrm{Vo}^{\text {subsurface }}$ or $\mathrm{Vo}^{\text {surface }}$ in the hydoxylated GDC is much easier than in the hydroxylated ceria. To create one Vo in hydroxylated ceria surface, $\mathrm{Vo}^{\text {subsurface }}$ is more favorable than $\mathrm{Vo}^{\text {surface }}$ at $\theta_{\mathrm{H}}<0.4$. In Type2, forming a $\mathrm{Vo}^{\text {subsurface }}$ can be favored until at a high hydroxyl coverage $\left(\theta_{\mathrm{H}}>0.8\right)$. By contrast, the $\mathrm{Vo}^{\text {surface }}$ is always more favorable than the $\mathrm{Vo}^{\text {subsurface }}$ in Typel at all hydroxyl coverages. For comparison. the Vo formation energy in the bulk (a $2 \times 2 \times 2$ cubic cell) is $3.16 \mathrm{eV}$, which is close to the value of $3.10 \mathrm{eV}$ calculated by Tang et al ${ }^{52}$. The Vo in the Type 2 GDC surface is more stable than the bulk Vo when the surface is fully hydroxylated. By contrast, the Vo is unstable in the Type1 GDC surface and in ceria at $\theta_{\mathrm{H}}>0.67$. A more detailed explanation of the relative stability of subsurface and surface oxygen vacancy in $\mathrm{CeO}_{2}$ with and without $\mathrm{Gd}$ doping at different $\mathrm{H}$ coverages are given in the supporting information at Page S8-S10. Therefore, GDC especially Type 2 can easily be reduced by forming hydroxyls and creating Vo. Since the reduced Type 2 is the more favorable than reduced Type1, Type 2 GDC is used as the GDC model for the following kinetic studies of Vo diffusion, water dissociation and hydroxyl decomposition.

\section{The reaction barriers for Vo diffusion, water dissociation and hydrogen formation at reduced GDC and reduced ceria.}

Barriers for Vo diffusion. Forming the $\mathrm{Vo}^{\text {surface }}$ in ceria, one $\mathrm{Ce}^{3+}$ ion locates in its nearestneighbored site and the other $\mathrm{Ce}^{3+}$ sites in the next-nearest-neighbored (NN-NNN) position. The same local distribution of localized electrons around the most stable $\mathrm{Vo}^{\text {surface }}$ has been reported by $\mathrm{Su}$ et $\mathrm{a}^{45}$ and Ganduglia-Pirovano et al. $^{23}$, using $\mathrm{U}_{\text {eff }}=4.5 \mathrm{eV}$. The calculated formation energy of the $\mathrm{Vo}^{\text {surface }}(2.18 \mathrm{eV})$ is close to the formation energy of 2.15 and $2.34 \mathrm{eV}$ calculated 
by Su et al. and by Ganduglia-Pirovano et al, respectively. Although the same local configuration is reported by using $\mathrm{PBE}+\mathrm{U}\left(\mathrm{U}_{\mathrm{eff}}=3.0 \mathrm{eV}\right)^{17}$, the total formation energy of the $\mathrm{Vo}^{\text {surface }}(2.78 \mathrm{eV})$ is about $0.6 \mathrm{eV}$ larger than the values calculated using $\mathrm{U}_{\text {eff }}=4.5 \mathrm{eV}$ in this work. This difference is caused by the lower stability of electrons localized in the $4 \mathrm{f}$ orbitals of ceria using lower $\mathrm{U}$ values, as discussed in the part of 'Methods'.

The most favorable Vo in GDC has electrons localized on two gadolinium atoms (Figure S4). Creating one more Vo, the most favorable configuration has the second Vo in the subsurface, where the two more compensating electrons localized on $2 \mathrm{Ce}^{3+}$ in the $\mathrm{NN}$ positions relative to the Vo. The formation energy of creating two Vo in the top surface is very close to creating one Vo in the top surface and the other Vo near the Gd in the subsurface. The less stable configuration is that the second Vo sites next to $2 \mathrm{Ce}^{3+}$. We calculate the barriers for oxygen vacancy diffusion from the subsurface configuration to the surface configuration in ceria with one Vo, and in GDC with one or two oxygen vacancies. In one vacancy system, the diffusion barrier is $0.15 \mathrm{eV}$ in GDC and $0.65 \mathrm{eV}$ in ceria, as shown in Figure 3(a). A 0.64 barrier for oxygen vacancy diffusion at the same Vo concentration in ceria has been reported by Chen et al. ${ }^{53}$ By contrast, the barrier for vacancy diffusion from the subsurface to the surface increases to $1.5 \mathrm{eV}$ when two vacancies are created in GDC as presented in Figure S8 in the supporting information. Although the mobility of oxygen decreases when two vacancies are present in GDC, it is still a facile reaction compared to the hydroxyl decomposition step for breaking the strong $\mathrm{O}-\mathrm{H}$ bond (having a $2.93 \mathrm{eV}$ activation barrier ${ }^{17}$ ). The ionic conductivity in ceria is improved significantly by the incorporation of gadolinium in the "one-vacancy" system. 

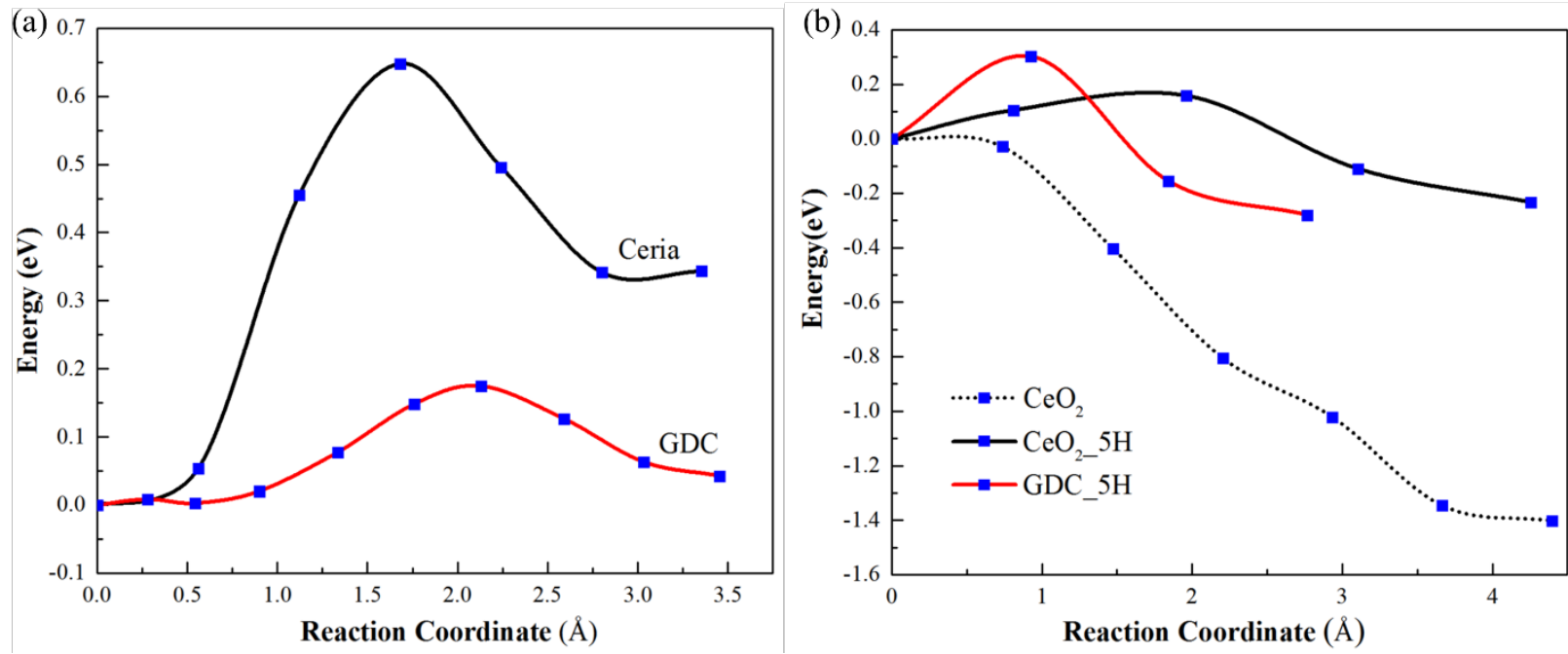

Figure 3. (a) Oxygen vacancy diffusion from the subsurface to the surface in ceria and GDC, respectively. (b) Water dissociation into hydroxyl groups over the ceria, the $5 \mathrm{H}$ covered ceria and the $5 \mathrm{H}$ covered GDC, respectively.

Barriers for water dissociation. It is easy for water adsorption on ceria or GDC surface after creating oxygen vacancy. The most stable configuration for adsorption of one water molecule on the $\mathrm{CeO}_{2}(111)$ surface is that it adsorbs next-nearest-neighbor to the oxygen vacancy. The water adsorption energy in ceria agrees well with previously reported results as shown in Table S2. On a highly reduced surface having five hydroxyls and an oxygen vacancy, the most stable site for water adsorption is near a cerium or gadolinium atom next to the $\mathrm{V}_{0}$ surface as shown in Figure S9. The reaction barriers for water dissociation into hydroxyls are calculated and presented in Figure 3(b). On the ceria surface having one $\mathrm{Vo}^{\text {surface }}$ (the dotted line), the water dissociates into two hydroxyls via the reaction of $\mathrm{H}_{2} \mathrm{O}_{\text {ads }}+2 \mathrm{Ce}^{3+}+\mathrm{V}_{\mathrm{o}}+\mathrm{O}^{2-} \rightarrow 2 \mathrm{OH}^{-}+$ $2 \mathrm{Ce}^{3+}$. The migration of the Vo from the subsurface to the surface provides a Vo site in the surface and can accommodate one $\mathrm{OH}$ coming from $\mathrm{H}_{2} \mathrm{O}$ slitting. The other $\mathrm{H}$ from $\mathrm{H}_{2} \mathrm{O}$ forms a second $\mathrm{OH}$ with the nearest-neighbor surface $\mathrm{O}$. The reaction barrier for water dissociation is 
close to zero and thus it is facile to perform water dissociation at the ceria surface. A similar reaction pathway and barrier for water dissociation has been demonstrated previously. ${ }^{17}$ No reaction path for water dissociation via the reaction of $\mathrm{H}_{2} \mathrm{O}_{\mathrm{ads}}+2 \mathrm{Gd}^{3+}+\mathrm{V}_{\mathrm{o}}+\mathrm{O}^{2-} \rightarrow 2 \mathrm{OH}^{-}+$ $2 \mathrm{Gd}^{3+}$ on the GDC with one $\mathrm{V}_{\mathrm{O}}^{\text {surface }}$, is presented, because the activation energy is negligible.

Because of the low barrier for water dissociation into hydroxyls, it is able to form more hydroxyls on the ceria and GDC surface. When the ceria and GDC surface is covered by five hydroxyls, we need to create one oxygen vacancy in the surface in order to form more hydroxyls via water dissociation. The water dissociates on such highly reduced ceria surface via the reaction of $\mathrm{H}_{2} \mathrm{O}_{\mathrm{ads}}+7 \mathrm{Ce}^{3+}+5 \mathrm{OH}^{-}+\mathrm{V}_{\mathrm{o}}+\mathrm{O}^{2-} \rightarrow 7 \mathrm{OH}^{-}+7 \mathrm{Ce}^{3+}$, where one $\mathrm{OH}$ from $\mathrm{H}_{2} \mathrm{O}$ takes the place of the Vo while the $\mathrm{H}$ of $\mathrm{H}_{2} \mathrm{O}$ reacts with one subsurface oxygen ion of the ceria to form one subsurface hydroxyl (subO-H). This subO-H is unfavorable compared to other surface hydroxyls as noticed from Figure 2. On the 5OH covered GDC surface, water dissociates into hydroxyls via the reaction of $\mathrm{H}_{2} \mathrm{O}_{\mathrm{ads}}+2 \mathrm{Gd}^{3+}+5 \mathrm{Ce}^{3+}+5 \mathrm{OH}^{-}+\mathrm{V}_{\mathrm{o}}+\mathrm{O}^{2-} \rightarrow 7 \mathrm{OH}^{-}+$ $2 \mathrm{Gd}^{3+}+5 \mathrm{Ce}^{3+}$, where one $\mathrm{OH}$ from water takes the place of the Vo while the $\mathrm{H}$ of water reacts with the subsurface oxygen that is nearest-neighbor to the Gd. Compared with the facile formation of the $2 \mathrm{OH}$ on the surface, the kinetic barrier for water dissociation to form the $7 \mathrm{OH}$ on the ceria and GDC increases slightly to 0.2 and $0.3 \mathrm{eV}$, respectively. Thus, it is easy to form fully and overly hydroxylated ceria and GDC via reactions between water and an oxygen vacancy.

Barriers for hydroxyl decomposition. After oxygen vacancies have diffused to the surface and reacted with the adsorbed water to form two hydroxyls on the ceria surfaces, the last step for hydrogen production is the hydroxyl decomposition, which is widely reported as the rate-determining step during many hydroxyl-associated reactions. ${ }^{11,17,44,52}$ The reaction barriers 
for hydroxyl decomposition on the ceria $\left(\mathrm{Ce}_{18} \mathrm{O}_{36}\right)$, GDC $\left(\mathrm{Gd}_{2} \mathrm{Ce}_{16} \mathrm{O}_{36}\right)$ and GDC with a compensating subsurface Vo (GDC_subVo, $\mathrm{Gd}_{2} \mathrm{Ce}_{16} \mathrm{O}_{35}$ ) are presented in Figure 4. The hydroxyl decomposition on the ceria surface proceeds via the reaction $2 \mathrm{OH}^{-}+2 \mathrm{Ce}^{3+} \rightarrow \mathrm{H}_{2}+$ $2 \mathrm{Ce}^{4+}+2 \mathrm{O}^{2-}$. The reaction is $2 \mathrm{OH}^{-}+2 \mathrm{Gd}^{3+} \rightarrow H_{2}+2 \mathrm{Gd}^{3+}+2 \mathrm{O}^{2-}+2 h^{+}$on the GDC surface and is $2 \mathrm{OH}^{-}+2 \mathrm{Gd}^{3+}+V_{0} \rightarrow H_{2}+2 \mathrm{Gd}^{3+}+V_{O}+2 \mathrm{O}^{2-}$ on the GDC_subVo surface.

The reaction pathways for hydroxyl decompositions are asymmetric and the transition states appear early when breaking the first $\mathrm{O}-\mathrm{H}$ bond. ${ }^{17,46} \mathrm{~A}$ vibrational analysis of the transition state for hydroxyl decomposition on these hydroxylated surfaces reveals a single mode with an imaginary frequency. The mode corresponds to an $\mathrm{H}$ moving over a $\mathrm{Gd} / \mathrm{Ce}$ ion while shortening the $\mathrm{H}-\mathrm{H}$ bond. At the TS for hydroxyl decomposition on the ceria, one $\mathrm{O}-\mathrm{H}$ bond is broken and one $\mathrm{Ce}^{3+}$ is oxidized to $\mathrm{Ce}^{4+}$, where the total magnetization of the ceria decreases from 1.96 to $0.98 \mu B$, as shown in Figure 4(b). The breaking of an O-H bond and an $\mathrm{H}-\mathrm{H}$ bond length of 2.02 $\AA$ in the transition state agree well with previous literature reports. ${ }^{17,54}$ After the transition state, breaking the second $\mathrm{O}-\mathrm{H}$ bond is downhill in energy as shown in Figure 4(a), which finally leads to the formation of one hydrogen molecule. This asymmetric reaction pathway leads to a $3.4 \mathrm{eV}$ barrier for hydroxyl decomposition over the ceria surface.

Similarly, the asymmetric reaction pathway is found for the hydrogen formation on the GDC and GDC_subVo, which respectively leads to a $5.2 \mathrm{eV}$ activation barrier and a $2.8 \mathrm{eV}$ barrier. The barrier decreases dramatically for hydrogen formation over the GDC reduced by creating one $\mathrm{Vo}^{\text {subsurface }}$ and forming two hydroxyls, compared with the partially hydroxylated (2H) GDC. This is because the final formation of the GDC_subVo $\left(\mathrm{Gd}_{2} \mathrm{Ce}_{16} \mathrm{O}_{35}\right)$ after the hydroxyl decomposition is more favored than the formation of the uncompensated GDC $\left(\mathrm{Gd}_{2} \mathrm{Ce}_{16} \mathrm{O}_{36}\right)$ surface as discussed in the section of "Distribution of $\mathrm{Gd}$ and oxygen vacancies (Vo) in 
$\mathrm{Gd}_{2} \mathrm{Ce}_{16} \mathrm{O}_{35}$ (111)". Therefore, our results indicate that the hydroxyl decomposition may proceed more easily over the highly hydroxylated GDC surface by creating oxygen vacancy and formation of hydroxyls. It has not been possible to identify $\mathrm{Ce}(\mathrm{Gd})-\mathrm{H}$ as a stable intermediate structure on the $2 \mathrm{H}^{*}$ surface because they easily relax into $\mathrm{H}_{2}$ or $2 \mathrm{OH}$.

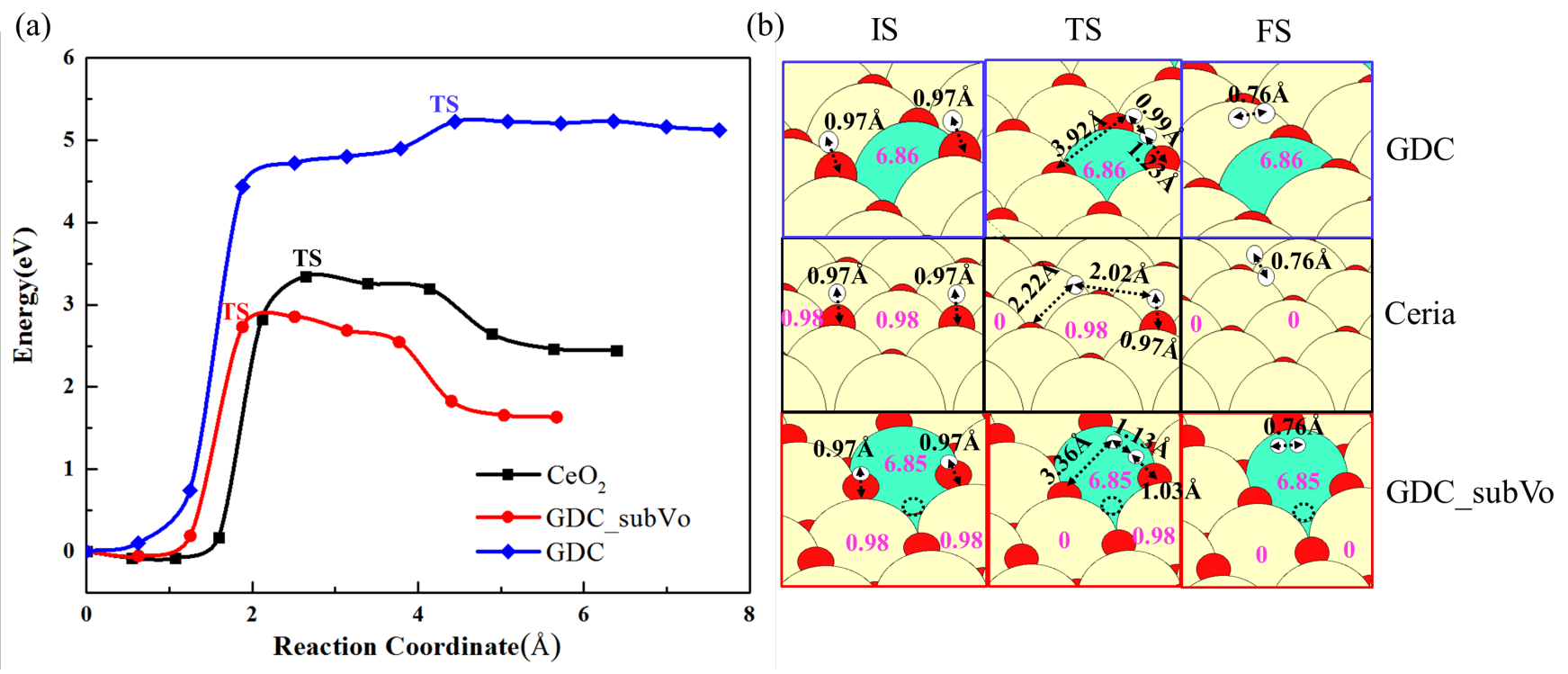

Figure 4. (a) Right panel: reaction pathways of the hydroxyl decomposition on ceria, GDC and GDC_subVo surfaces, respectively. (b) Left panel: the configurations of the initial state (IS), transition state (TS) and final state (FS) along each reaction pathways. Bond lengths in surface hydroxyl and $\mathrm{H}_{2}$, as well as the magnetization $(\mu B)$ of the each reaction states are labeled. The color for each kinds of atoms is used the same as in Figure 1. The dashed circle indicates the oxygen vacancy in the subsurface of GDC.

The reaction barriers for hydrogen formation on the overly hydroxylated ceria and GDC are presented in Figure 5. As discussed in the section of "Barriers for water dissociation", the water dissociates into hydroxyls on the $5 \mathrm{OH}$ covered ceria surface via the reaction of $\mathrm{H}_{2} \mathrm{O}_{\text {ads }}+$ $7 \mathrm{Ce}^{3+}+5 \mathrm{OH}^{-}+\mathrm{V}_{\mathrm{o}}+\mathrm{O}^{2-} \rightarrow 7 \mathrm{OH}^{-}+7 \mathrm{Ce}^{3+}$, where the $\mathrm{H}$ of water reacts with one subsurface 
oxygen ion of the ceria to form one subsurface hydroxyl (subO-H). This reaction is competed by $\mathrm{H}_{2} \mathrm{O}_{\text {ads }}+5 \mathrm{OH}^{-}+7 \mathrm{Ce}^{3+}+\mathrm{V}_{\mathrm{o}} \rightarrow 6 \mathrm{OH}^{-}+\mathrm{Ce}^{4+}+\mathrm{Ce}^{4+} \mathrm{H}^{-}+5 \mathrm{Ce}^{3+}$, where the $\mathrm{H}$ from water binds to the metal ions and thus form Ce-H moiety in the surface. Two electrons from the $4 \mathrm{f}$ shell of $2 \mathrm{Ce}^{3+}$ contribute to the formation of the $\mathrm{Ce}^{4+} \mathrm{H}^{-}$and one $\mathrm{Ce}^{4+}$ (i.e. oxidation of ceria). In this $\mathrm{Ce}-\mathrm{H}$ system, there are total $5 \mathrm{Ce}^{3+}$ and the total magnetization of the system is $5.0 \mu B$ as presented in Figure 5 (c). For water dissociation in the GDC system, the Gd-H moiety forms via the reaction of $\mathrm{H}_{2} \mathrm{O}_{\mathrm{ads}}+5 \mathrm{OH}^{-}+5 \mathrm{Ce}^{3+}+2 \mathrm{Gd}^{3+}+\mathrm{V}_{\mathrm{o}} \rightarrow 6 \mathrm{OH}^{-}+2 \mathrm{Ce}^{4+}+\mathrm{Gd}^{3+} \mathrm{H}^{-}+$ $3 C e^{3+}+G d^{3+}$. The $4 \mathrm{f}^{1}$ of $2 \mathrm{Ce}^{3+}$ donates two electrons, which contributes to the formation of the $\mathrm{Gd}^{3+} \mathrm{H}^{-}$. In the $\mathrm{Gd}-\mathrm{H}$ system, the magnetization of each $\mathrm{Gd}^{3+}$ is $7.0 \mu B$ and there are $3 \mathrm{Ce}^{3+}$ with the magnetization of $1.0 \mu B$ for each, as shown in Figure 5 (c).

The binding of $\mathrm{H}$ to $\mathrm{Ce}$ in the surface is about $0.9 \mathrm{eV}$ weaker than the binding to an oxygen in the subsurface as shown in Figure 5 (a). However, the $\mathrm{Ce}-\mathrm{H}$ bond is 0.28 and $1.15 \mathrm{eV}$ weaker than the $\mathrm{O}-\mathrm{H}$ bond when using a $\mathrm{U}_{\text {eff }}$ value of 3.0 and $5.0 \mathrm{eV}$, respectively, which indicates these bindings are strongly dependent on the values of $U_{\text {eff }}$ corrections. The sensitivity to the choice of $\mathrm{U}_{\text {eff }}$ arises from the fact that there are $5 \mathrm{Ce}^{3+}$ ions in the surface with formation of one $\mathrm{Ce}-\mathrm{H}$ and six $\mathrm{O}-\mathrm{H}$, while the surface with formation of seven $\mathrm{O}-\mathrm{H}$ has $7 \mathrm{Ce}^{3+}$ ions. In the overly hydroxylated GDC, the binding between $\mathrm{H}$ and the oxygen next to the Gd in the subsurface is 1.9 $\mathrm{eV}$ stronger than the binding between $\mathrm{H}$ and $\mathrm{Gd}$ in the surface as presented in Figure 5 (b). Because of the strong binding between $\mathrm{H}$ and oxygen in the subsurface, the direct breaking of the O-H bond for HER is difficult. Herein, for hydroxyl decomposition on such overly hydroxylated surfaces, the reaction pathways were split into two independent paths via a $\mathrm{Ce}-\mathrm{H}$ and $\mathrm{Gd}-\mathrm{H}$ intermediate, respectively on the overly hydroxylated ceria and GDC surface. Path I involves the reaction of breaking the $\mathrm{O}-\mathrm{H}$ bond in the subsurface to form Me- $\mathrm{H}(\mathrm{Gd}-\mathrm{H}$ or $\mathrm{Ce}-\mathrm{H})$ 
intermediates. Path II involves the reaction between the Me- $\mathrm{H}$ and the nearby $\mathrm{O}-\mathrm{H}$, finally leading to the formation of $\mathrm{H}_{2}$. The reaction along Path I is $\mathrm{OH}_{\text {subsurface }}^{-}+2 \mathrm{Ce}^{3+}+\mathrm{Gd}^{3+} \rightarrow$ $2 \mathrm{Ce}^{4+}+\mathrm{Gd}^{3+} \mathrm{H}^{-}+\mathrm{O}_{\text {subsurface }}^{2-}$ on the $\mathrm{GDC}$ surface and $\mathrm{OH}_{\text {subsurface }}^{-}+2 \mathrm{Ce}^{3+} \rightarrow \mathrm{Ce}^{4+}+$ $\mathrm{Ce}^{4+} H^{-}+O_{\text {subsurface }}^{2-}$ on the ceria surface. The reaction along Path II is $O H_{\text {surface }}^{-}+\mathrm{Gd}^{3+} H^{-} \rightarrow$ $\mathrm{Gd}^{3+}+\mathrm{H}_{2}+\mathrm{O}_{\text {surface }}^{2-}$ on the GDC surface and $\mathrm{OH}_{\text {surface }}^{-}+\mathrm{Ce}^{4+} \mathrm{H}^{-} \rightarrow \mathrm{Ce}^{4+}+\mathrm{H}_{2}+$ $O_{\text {surface }}^{2-}$ on the ceria surface.

For the reaction along Path I on ceria, breaking the $\mathrm{O}-\mathrm{H}$ bond in the subsurface of the overly hydroxylated ceria is difficult, leading to a $2.0 \mathrm{eV}$ activation barrier. At the TS1, the $\mathrm{Ce}^{3+}$ in the subsurface is oxidized to $\mathrm{Ce}^{4+}$, which is followed by the oxidation of second $\mathrm{Ce}^{3+}$ in the top surface to form the Ce-H. For the reaction along path I over the overly hydroxylated GDC, the barrier is $2.5 \mathrm{eV}$, where the $\mathrm{O}-\mathrm{H}$ bond of TS1 is broken but the total magnetization remains unchanged (i.e., no $\mathrm{Ce}^{3+}$ or $\mathrm{Gd}^{3+}$ is oxidized). The higher barrier in GDC system arises from the higher stability of the overly hydroxylated GDC as discussed in the part of $\mathrm{E}_{\mathrm{H}}$ (presented in Figure 2). However, the HER proceeds easily along Path II, having a $0.7 \mathrm{eV}$ and $0.05 \mathrm{eV}$ barrier on the overly hydroxylated ceria and GDC, respectively. By comparing Path I and Path II, it is noticed that breaking the O-H bond in the subsurface in Path I is the most difficult step. This indicates that if the formation of Me- $\mathrm{H}$ moiety becomes more favorable by adding a substitutional dopant, the reaction along Path I can proceed with a lower activation barrier for $\mathrm{H}_{2}$ formation. 

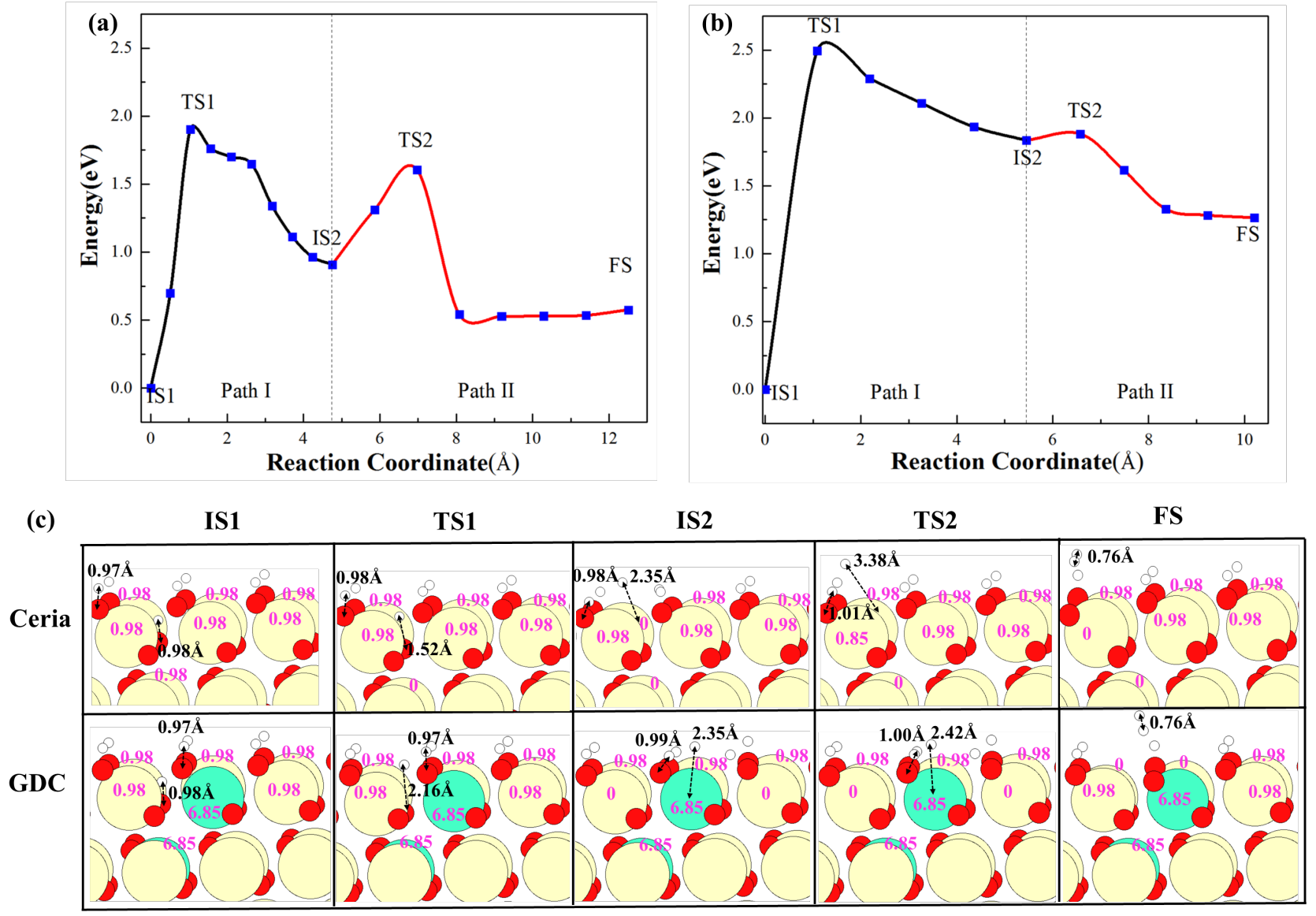

Figure 5. Energy diagrams for hydroxyl decomposition into $\mathrm{H}_{2}$ on the overly hydroxylated $\mathrm{CeO}_{2}$ $(7 \mathrm{H})$ surface (a) and on the overly hydroxylated GDC (7H) surface (b). (c) Side views of the optimized structures for each intermediates and transition states (the top views are given in Figure $\mathrm{S} 10$ in the supporting information). The bond lengths of the $\mathrm{O}-\mathrm{H}, \mathrm{Ce}-\mathrm{H}$ and $\mathrm{Gd}-\mathrm{H}$ involved in the reactions are labeled. In addition, the magnetization $(\mu B)$ of the each reaction states are marked with pink.

\section{The reaction pathways for hydrogen production at reduced GDC and ceria.}

Based on the previous discussions on the configurations of the reduced surface and the kinetic barriers of each reaction steps at the reduced surface, the free energy of the intermediates at each reaction steps during the WSR is calculated. Because of the operation for electrochemical 
reactions over GDC is at temperatures $773-1073 \mathrm{~K},{ }^{19,20}$ the free energy diagram at $800 \mathrm{~K}$ is investigated and a higher temperature $(1200 \mathrm{~K})$ is investigated for comparison. The simplified free energy diagram of HER on the ceria and GDC are shown in Figure 6. To calculate the relative free energy of the reduced surfaces at each reaction step, the surface without any vacancies or hydroxyl groups in ceria and GDC is chosen as reference surfaces. The reduced surfaces are formed via the reaction between vacancies, oxygen and water at the reference surface. On the bias of this reaction, the free energies for each reduced surface are calculated (see more details at page S11 and S12 in the supporting information). The formation of the fully hydroxylated (covered by 6H) GDC and ceria is more favorable than the other $\mathrm{H}$ coverage at 400 $\mathrm{K}<\mathrm{T}<1200 \mathrm{~K}$, as presented in Figure S11. Besides, it is easier to form the overly hydroxylated (7H) GDC than ceria at $400 \mathrm{~K}<\mathrm{T}<1200 \mathrm{~K}$.

At $800 \mathrm{~K}$, a 3.20 and $2.60 \mathrm{eV}$ enthalpy barrier is required for the hydrogen formation over the partially hydroxylated ceria and GDC surface, respectively as shown in Figure 6. Here, the transition state occurs with the first $\mathrm{O}-\mathrm{H}$ bond breaking in hydroxyl coupled with electron transfer from $\mathrm{Ce}^{3+}$ as discussed in the part of "Barriers for hydroxyl decomposition". Compared to the partially hydroxylated pathways, the HER proceeds more efficiently via the $\mathrm{Ce}-\mathrm{H}$ and Gd$\mathrm{H}$ intermediates on the overly hydroxylated ceria and GDC surfaces, respectively, where we find a 1.60 and $2.20 \mathrm{eV}$ kinetic barriers for the $\mathrm{H}_{2}$ formation, respectively. However, the reaction energy required to form the $\mathrm{Ce}-\mathrm{H}$ intermediate on fully hydroxylated ceria is $1.31 \mathrm{eV}$, while only $0.46 \mathrm{eV}$ is required for the formation of the Gd-H on the fully hydroxylated GDC because of the stabilization of the reduced states by the incorporation of Gd. Thus, it is more difficult to form overly hydroxylated ceria and overall free energy barrier for the HER on the overly hydroxylated ceria surface is $2.91 \mathrm{eV}$. By contrast, $2.67 \mathrm{eV}$ is required for the hydrogen production on the 
overly hydroxylated GDC. These results indicate the reaction activity of the HER on ceria is significantly improved by the incorporation of gadolinium. In addition, if the formation of the $7 \mathrm{H}$ is favorable and the Metal-H is stabilized by adding a substitutional dopant in ceria, the total free energy for the $\mathrm{H}_{2}$ formation will decrease.
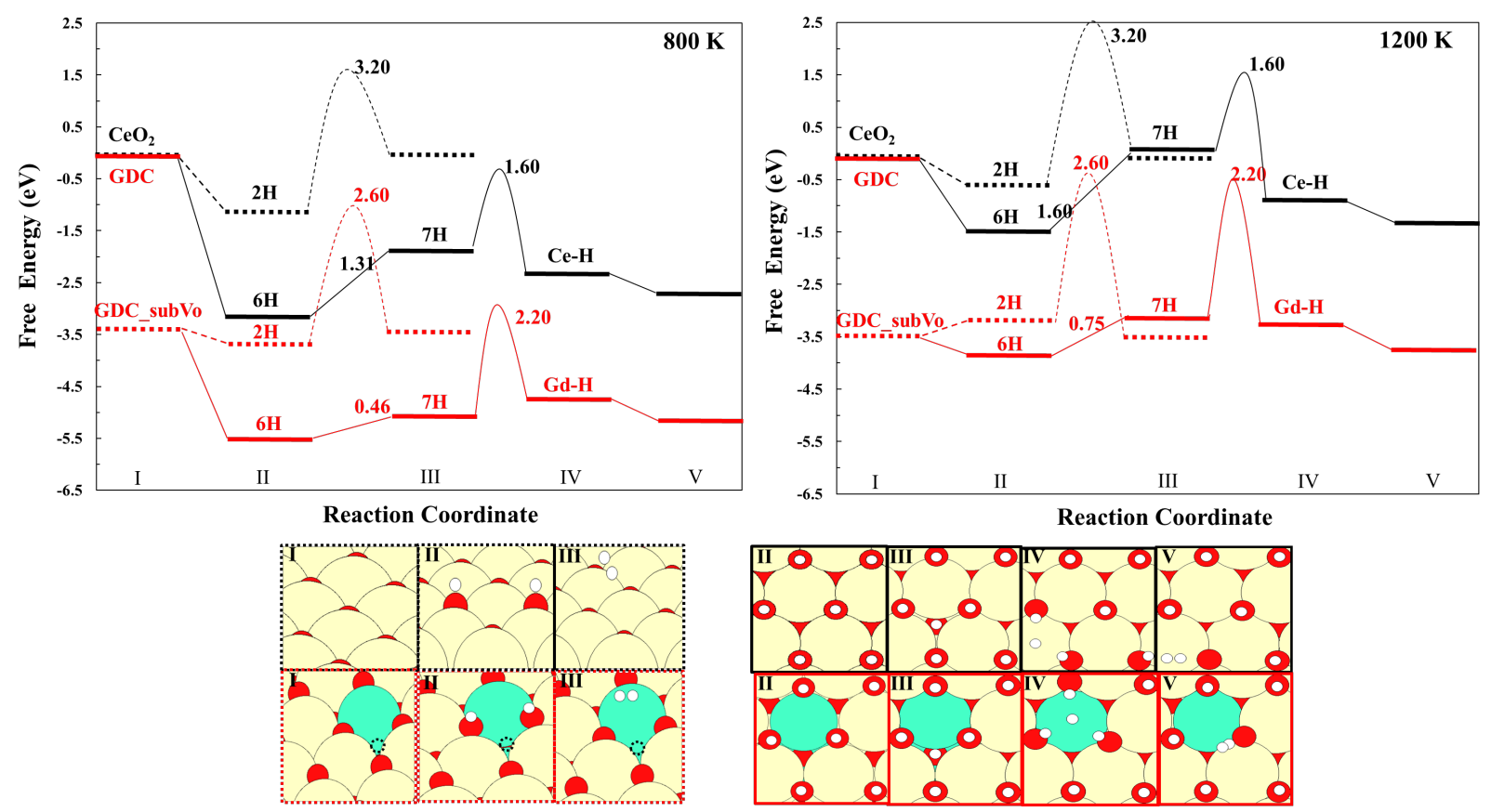

Figure 6. Top panel: Free energy of the intermediates during the hydrogen evolution reaction on the partially $(2 \mathrm{H})$ and overly $(7 \mathrm{H})$ hydroxylated $\mathrm{GDC}$ and $\mathrm{CeO}_{2}$, at 800 and $1200 \mathrm{~K}$, respectively. Bottom panel: Atomic configurations of reaction intermediates over the four different surfaces. The color for each kinds of atoms is used the same as in Figure 4. The dashed circle stands for an oxygen vacancy.

As temperature increases to $1200 \mathrm{~K}$, the free energies of all intermediates increase mainly due to the loss of gas phase entropy upon adsorption. ${ }^{17} \mathrm{~A}$ significant increase is found for the reaction free energy to form the overly hydroxylated surfaces, which increases to 1.60 and 0.75 $\mathrm{eV}$ in ceria and GDC, respectively. The formation of the overly reduced ceria competes heavily 
with the water adsorption/desorption at high temperature (Figure S12), which prevents the formation the highly reduced states. However, the hydroxyl decomposition remains to be the rate-determining step, which can be seen from the full reaction pathways in Figure S12 in the supporting information. At $1200 \mathrm{~K}$, the lowest energy cost reaction remains to proceed via the Gd-H intermediate on the overly hydroxylated GDC. The operating temperature for the HER on GDC should be higher than $800 \mathrm{~K}$ to reach the same rate as on Pt at $400 \mathrm{~K}$ (Figure S13 in the supporting information). The predicted operating temperature is consistent with the experimental operating temperature range $(773-1073 \mathrm{~K}) \cdot{ }^{19,20}$ However, temperatures higher than $900 \mathrm{~K}$ are required for the HER on ceria. Therefore, the HER is allowed to proceed at lower temperature on GDC than on un-doped ceria. The reactivity of the WSR on ceria is improved by the incorporation of gadolinium.

\section{Conclusions}

Using the DFT $+\mathrm{U}$ method, we have studied configurations of reduced ceria and reduced GDC via creating vacancies and forming hydroxyls. We find that Gd can distribute freely between the top surface or subsurface of the $\mathrm{Gd}_{2} \mathrm{Ce}_{16} \mathrm{O}_{35}(111)$ surface at $11 \% \mathrm{Gd}$ concentration. The vacancy and hydroxyl formation energy in GDC was more negative than in pure ceria. Thus, it is much easier to form highly reduced GDC than to form highly reduced ceria via creating vacancies and forming hydroxyls. Then, the mechanism of water splitting on the GDC surface compared to pure ceria was revealed by the kinetic investigations. We observed that one vacancy diffusion in the GDC surface was faster than in the ceria surface. The following step for the water dissociation on both GDC and ceria surface was facile even at very high hydrogen coverage. However, there is a large barrier for hydroxyl decomposition on the partially hydroxylated ceria and GDC. The reaction activity for the HER was improved significantly via the Gd-H 
intermediate on the overly hydroxylated GDC surface under the operating temperature (800 and $1200 \mathrm{~K}$ ), which is attributed to the much favorable formation of the $\mathrm{Gd}-\mathrm{H}$ than $\mathrm{Ce}-\mathrm{H}$ intermediate.

In conclusion, the incorporation of Gd plays an important role in stabilizing the intermediates and transition states for hydroxyl decomposition and further enhancing performance of ceria for water splitting. Therefore, a dopant that stabilizes the reduced ceria surface and has strong binding to hydrogen is capable of effectively improving the reaction activity of ceria for renewable hydrogen production in SOEC. Our findings give insight in the mechanism of water splitting in GDC and ceria, which help for the design of ceria-based electrocatalyst for renewable hydrogen production via water splitting reaction.

\section{ASSOCIATED CONTENT}

\section{Supporting Information}

Figures containing the configurations of the $\mathrm{Ce}_{18} \mathrm{O}_{36}$ (111) surface, reduced ceria and GDC surface via forming one oxygen vacancy or hydroxyl and also the most stable configurations of water adsorption, overly hydroxylated surface and hydrogen desorption on ceria and GDC. Barriers for hydroxyl decomposition into $\mathrm{H}_{2}$ and Vo formation energy as a function of the $\mathrm{U}$ correction on $\mathrm{Ce} 4 \mathrm{f}$ states. The pathway for vacancy diffusion in a two-vacancy system of GDC. Free energy of the $\mathrm{H}$ covered ceria and GDC as a function of hydroxyl coverage. Free energy diagrams for water splitting at 800 and $1200 \mathrm{~K}$. Views of the optimized structures for each intermediates and transition states during the hydroxyl decomposition into $\mathrm{H}_{2}$. Discussions of the relative stability of $\mathrm{V}_{\mathrm{O}}^{\text {subsurface }}$ and $\mathrm{V}_{\mathrm{O}}^{\text {surface }}$ in the ceria with and without Gd doping at different hydroxyl coverages. Tables of DFT energies for vacancy formation, vacancy diffusion, and water 
adsorption and dissociation. Details of methods for calculating free energies of the reduced surface.

\section{ACKNOWLEDGMENTS}

This work is supported by the Velux Foundations through the research center V-Sustain (grant number 9455).

\section{REFERENCE}

(1) Jen, H.-W.; Graham, G. W.; Chun, W.; McCabe, R. W.; Cuif, J.-P.; Deutsch, S. E.; Touret, O. Characterization of Model Automotive Exhaust Catalysts: Pd on Ceria and CeriaZirconia Supports. Catal. Today 1999, 50, 309-328.

(2) Oh, S. H.; Hoflund, G. B. Chemical State Study of Palladium Powder and CeriaSupported Palladium during Low-Temperature CO Oxidation. J. Phys. Chem. A 2006, 110 (24), 7609-7613.

(3) Di Monte, R.; Kašpar, J. On the Role of Oxygen Storage in Three-Way Catalysis. Top. Catal. 2004, $28(1-4), 47-57$.

(4) Bunluesin, T.; Gorte, R. J.; Graham, G. W. Studies of the Water-Gas-Shift Reaction on Ceria-Supported Pt, Pd, and Rh: Implications for Oxygen-Storage Properties. Appl. Catal. B Environ. 1998, 15 (1-2), 107-114.

(5) Fu, Q. Active Nonmetallic Au and Pt Species on Ceria-Based Water-Gas Shift Catalysts. Science (80-. ). 2003, 301 (5635), 935-938.

(6) Hilaire, S.; Wang, X.; Luo, T.; Gorte, R. J.; Wagner, J. A Comparative Study of WaterGas-Shift Reaction over Ceria-Supported Metallic Catalysts. Appl. Catal. A Gen. 2004, $258(2), 271-276$.

(7) Otsuka, K.; Hatano, M.; Morikawa, A. Hydrogen from Water by Reduced Cerium Oxide. J. Catal. 1983, 79 (2), 493-496.

(8) Abanades, S.; Legal, A.; Cordier, A.; Peraudeau, G.; Flamant, G.; Julbe, A. Investigation of Reactive Cerium-Based Oxides for $\mathrm{H}_{2}$ Production by Thermochemical Two-Step 
Water-Splitting. J. Mater. Sci. 2010, 45 (15), 4163-4173.

(9) Fergus, J. W. Electrolytes for Solid Oxide Fuel Cells. J. Power Sources 2006, 162 (1), 3040.

(10) Shao, Z.; Haile, S. M.; Ahn, J.; Ronney, P. D.; Zhan, Z.; Barnett, S. A. A Thermally SelfSustained Micro Solid-Oxide Fuel-Cell Stack with High Power Density. Nature 2005, 435 (7043), 795-798.

(11) Feng, Z. A.; El Gabaly, F.; Ye, X.; Shen, Z.-X.; Chueh, W. C. Fast Vacancy-Mediated Oxygen Ion Incorporation across the Ceria-gas Electrochemical Interface. Nat. Commun. 2014, 5, 1-9.

(12) Zhang, C.; Yu, Y.; Grass, M. E.; Dejoie, C.; Ding, W.; Gaskell, K.; Jabeen, N.; Hong, Y. P.; Shavorskiy, A.; Bluhm, H.; et al. Mechanistic Studies of Water Electrolysis and Hydrogen Electro-Oxidation on High Temperature Ceria-Based Solid Oxide Electrochemical Cells. J. Am. Chem. Soc. 2013, 135 (31), 11572-11579.

(13) Irvine, J. T. S.; Neagu, D.; Verbraeken, M. C.; Chatzichristodoulou, C.; Graves, C.; Mogensen, M. B. Evolution of the Electrochemical Interface in High-Temperature Fuel Cells and Electrolysers. Nat. Energy 2016, 1 (1), 15014.

(14) Hauch, A.; Mogensen, M.; Hagen, A. Ni/YSZ Electrode Degradation Studied by Impedance Spectroscopy - Effect of p $\left(\mathrm{H}_{2} \mathrm{O}\right)$. Solid State Ionics 2011, 192 (1), 547-551.

(15) Chueh, W. C.; Hao, Y.; Jung, W.; Haile, S. M. High Electrochemical Activity of the Oxide Phase in Model Ceria-Pt and Ceria-Ni Composite Anodes. Nat. Mater. 2011, 11 (2), 155-161.

(16) Zhang, C.; Grass, M. E.; McDaniel, A. H.; Decaluwe, S. C.; Gabaly, F. El; Liu, Z.; McCarty, K. F.; Farrow, R. L.; Linne, M. A.; Hussain, Z.; et al. Measuring Fundamental Properties in Operating Solid Oxide Electrochemical Cells by Using in Situ X-Ray Photoelectron Spectroscopy. Nat. Mater. 2010, 9 (11), 944-949.

(17) Hansen, H. A.; Wolverton, C. Kinetics and Thermodynamics of $\mathrm{H}_{2} \mathrm{O}$ Dissociation on Reduced $\mathrm{CeO}_{2}$ (111). J. Phys. Chem. C 2014, 118 (47), 27402-27414. 
(18) Inaba, H.; Sagawa, R.; Hayashi, H.; Kawamura, K. Molecular Dynamics Simulation of Gadolinia-Doped Ceria. Solid State Ionics 1999, 122 (1-4), 95-103.

(19) Ni, M.; Leung, M. K. H.; Leung, D. Y. C. Technological Development of Hydrogen Production by Solid Oxide Electrolyzer Cell (SOEC). Int. J. Hydrogen Energy 2008, 33 (9), 2337-2354.

(20) Zhang, C.; Li, C. J.; Zhang, G.; Ning, X. J.; Li, C. X.; Liao, H.; Coddet, C. Ionic Conductivity and Its Temperature Dependence of Atmospheric Plasma-Sprayed Yttria Stabilized Zirconia Electrolyte. Mater. Sci. Eng. B Solid-State Mater. Adv. Technol. 2007, $137(1-3), 24-30$.

(21) Paier, J.; Penschke, C.; Sauer, J. Oxygen Defects and Surface Chemistry of Ceria: Quantum Chemical Studies Compared to Experiment. Chem. Rev. 2013, 113 (6), 3949_ 3985.

(22) Naghavi, S. S.; Emery, A. A.; Hansen, H. A.; Zhou, F.; Ozolins, V.; Wolverton, C. Giant Onsite Electronic Entropy Enhances the Performance of Ceria for Water Splitting. Nat. Commun. 2017, 8 (1), 1-6.

(23) Ganduglia-Pirovano, M. V.; Da Silva, J. L. F.; Sauer, J. Density-Functional Calculations of the Structure of near-Surface Oxygen Vacancies and Electron Localization on $\mathrm{CeO}_{2}(111)$. Phys. Rev. Lett. 2009, 102 (2), 1-4.

(24) Yang, Z.; Wang, Q.; Wei, S.; Ma, D.; Sun, Q. The Effect of Environment on the Reaction of Water on the Ceria (111) Surface : A DFT + U Study. J. Phys. Chem. C 2010, No. 114, $14891-14899$.

(25) Mullins, D. R.; Albrecht, P. M.; Chen, T. L.; Calaza, F. C.; Biegalski, M. D.; Christen, H. M.; Overbury, S. H. Water Dissociation on $\mathrm{CeO}_{2}(100)$ and $\mathrm{CeO}_{2}(111)$ Thin Films. J. Phys. Chem. C 2012, 116 (36), 19419-19428.

(26) Lykhach, Y.; Johánek, V.; Aleksandrov, H. A.; Kozlov, S. M.; Happel, M.; Skála, T.; Petkov, P. S.; Tsud, N.; Vayssilov, G. N.; Prince, K. C.; et al. Water Chemistry on Model Ceria and Pt/Ceria Catalysts. J. Phys. Chem. C 2012, 116 (22), 12103-12113.

(27) Kundakovic, L.; Mullins, D. R.; Overbury, S. H. Adsorption and Reaction of $\mathrm{H}_{2} \mathrm{O}$ and CO 27 
on Oxidized and Reduced $\mathrm{Rh} / \mathrm{CeO}_{\mathrm{x}}(111)$ Surfaces. Surf. Sci. 2000, 457 (1), 51-62.

(28) Aparicio-Anglès, X.; Roldan, A.; De Leeuw, N. H. Gadolinium-Vacancy Clusters in the (111) Surface of Gadolinium-Doped Ceria: A Density Functional Theory Study. Chem. Mater. 2015, 27 (23), 7910-7917.

(29) Dholabhai, P. P.; Adams, J. B.; Crozier, P.; Sharma, R. A Density Functional Study of Defect Migration in Gadolinium Doped Ceria. Phys. Chem. Chem. Phys. 2010, 12 (28), 7904.

(30) Grieshammer, S.; Grope, B. O. H.; Koettgen, J.; Martin, M. A Combined DFT + U and Monte Carlo Study on Rare Earth Doped Ceria. Phys. Chem. Chem. Phys. 2014, 16 (21), 9974.

(31) Kresse, G.; Furthmüller, J. Efficient Iterative Schemes for Ab Initio Total-Energy Calculations Using a Plane-Wave Basis Set. Phys. Rev. B 1996, 54 (16), 11169-11186.

(32) Kresse, G.; Furthmüller, J. Efficiency of Ab-Initio Total Energy Calculations for Metals and Semiconductors Using a Plane-Wave Basis Set. Comput. Mater. Sci. 1996, 6 (1), 1550.

(33) Kresse, G.; Hafner, J. Ab Initio Molecular Dynamics for Open-Shell Transition Metals. Phys. Rev. B 1993, 48 (17), 13115-13118.

(34) Blöchl, P. E. Projector Augmented-Wave Method. Phys. Rev. B 1994, 50 (24), 1795317979.

(35) Perdew, J. P.; Burke, K.; Ernzerhof, M. Generalized Gradient Approximation Made Simple. Phys. Rev. Lett. 1996, 77 (18), 3865-3868.

(36) Loschen, C.; Carrasco, J.; Neyman, K. M.; Illas, F. First-Principles LDA+U and GGA+U Study of Cerium Oxides: Dependence on the Effective U Parameter. Phys. Rev. B Condens. Matter Mater. Phys. 2007, 75 (3), 1-8.

(37) Vanpoucke, D. E. P.; Bultinck, P.; Cottenier, S.; Van Speybroeck, V.; Van Driessche, I. Aliovalent Doping of $\mathrm{CeO}_{2}$ : DFT Study of Oxidation State and Vacancy Effects. J. Mater. Chem. A 2014, 2 (33), 13723-13737. 
(38) Murgida, G. E.; Ganduglia-Pirovano, M. V. Evidence for Subsurface Ordering of Oxygen Vacancies on the Reduced $\mathrm{CeO}_{2}$ (111) Surface Using Density-Functional and Statistical Calculations. Phys. Rev. Lett. 2013, 110 (24), 1-5.

(39) Huang, M.; Fabris, S. CO Adsorption and Oxidation on Ceria Surfaces from DFT + U Calculations. J. Phys. Chem. C 2008, 112, 8643.

(40) Castleton, C. W. M.; Kullgren, J.; Hermansson, K. Tuning LDA+U for Electron Localization and Structure at Oxygen Vacancies in Ceria. J. Chem. Phys. 2007, 127 (24).

(41) Da Silva, J. L. F.; Ganduglia-Pirovano, M. V.; Sauer, J.; Bayer, V.; Kresse, G. Hybrid Functionals Applied to Rare-Earth Oxides: The Example of Ceria. Phys. Rev. B - Condens. Matter Mater. Phys. 2007, 75 (4), 19-24.

(42) Kresse, G.; Blaha, P.; Da Silva, J. L. F.; Ganduglia-Pirovano, M. V. Comment on 'Taming Multiple Valency with Density Functionals: A Case Study of Defective Ceria'. Phys. Rev. B - Condens. Matter Mater. Phys. 2005, 72 (23), 1-2.

(43) Farra, R.; García-Melchor, M.; Eichelbaum, M.; Hashagen, M.; Frandsen, W.; Allan, J.; Girgsdies, F.; Szentmiklósi, L.; López, N.; Teschner, D. Promoted Ceria: A Structural, Catalytic, and Computational Study. ACS Catal. 2013, 3 (10), 2256-2268.

(44) Capdevila-Cortada, M.; García-Melchor, M.; López, N. Unraveling the Structure Sensitivity in Methanol Conversion on $\mathrm{CeO}_{2}$ : A DFT + U Study. J. Catal. 2015, 327, 5864.

(45) Su, Y. Q.; Filot, I. A. W.; Liu, J. X.; Tranca, I.; Hensen, E. J. M. Charge Transport over the Defective $\mathrm{CeO}_{2}$ (111) Surface. Chem. Mater. 2016, 28 (16), 5652-5658.

(46) Fernández-Torre, D.; Carrasco, J.; Ganduglia-Pirovano, M. V.; Pérez, R. Hydrogen Activation, Diffusion, and Clustering on $\mathrm{CeO}_{2}(111)$ : A DFT+ U Study. J. Chem. Phys. 2014, $141(1)$.

(47) Gerward, L.; Staun Olsen, J.; Petit, L.; Vaitheeswaran, G.; Kanchana, V.; Svane, A. Bulk Modulus of $\mathrm{CeO}_{2}$ and $\mathrm{PrO}_{2}$ - An Experimental and Theoretical Study. J. Alloys Compd. 2005, 400 (1-2), 56-61. 
(48) Wang, H.; Chroneos, A.; Schwingenschlögl, U. Impact of Doping on the Ionic Conductivity of Ceria: A Comprehensive Model. J. Chem. Phys. 2013, 138 (22).

(49) Minervini, L. Defect Cluster Formation in $\mathrm{M}_{2} \mathrm{O}_{3}$-Doped $\mathrm{CeO}_{2}$. Solid State Ionics 1999, $116(3-4), 339-349$.

(50) Henkelman, G.; Uberuaga, B. P.; Jónsson, H. Climbing Image Nudged Elastic Band Method for Finding Saddle Points and Minimum Energy Paths. J. Chem. Phys. 2000, 113 (22), 9901-9904.

(51) Li, H.; Wang, H.; Gong, X.; Guo, Y.; Guo, Y.; Lu, G.; Hu, P. Multiple Configurations of the Two Excess 4 f Electrons on Defective $\mathrm{CeO}_{2}$ ( 111 ): Origin and Implications. 2009, 2 (111), 2-5.

(52) Tang, Y.; Zhang, H.; Cui, L.; Ouyang, C.; Shi, S.; Tang, W.; Li, H.; Lee, J. S.; Chen, L. First-Principles Investigation on Redox Properties of $\mathrm{M}$-Doped $\mathrm{CeO}_{2}(\mathrm{M}=\mathrm{Mn}, \mathrm{Pr}, \mathrm{Sn}, \mathrm{Zr})$. Phys. Rev. B - Condens. Matter Mater. Phys. 2010, 82 (12), 1-9.

(53) Truhlar, D. G. Valence Bond Theory for Chemical Dynamics. J. Comput. Chem. 2009, 28 (1), 73-86.

(54) Garc, M. Homolytic Products from Heterolytic Paths in $\mathrm{H}_{2}$ Dissociation on Metal Oxides : The Example of $\mathrm{CeO}_{2}$. J. Phys. Chem. C 2014, 118, 10921-10926. 


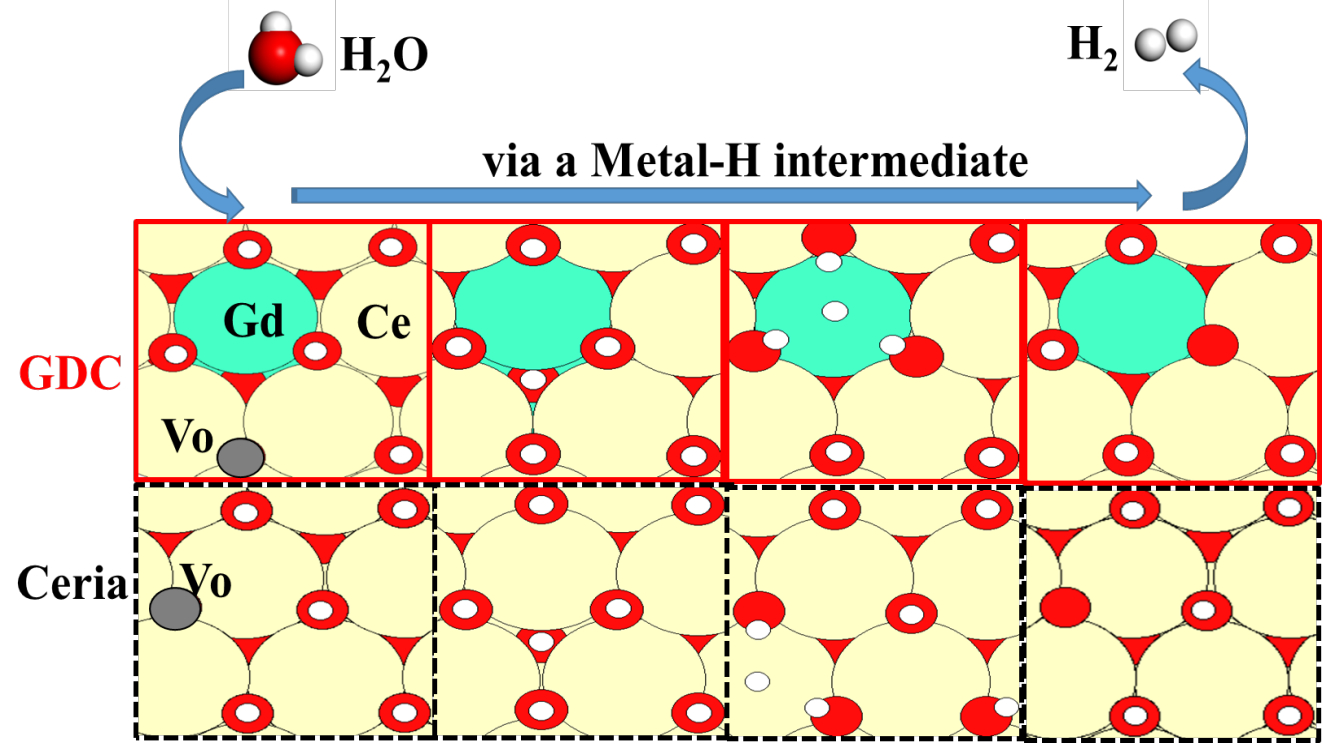

